\title{
A case of nimesulide induced toxic epidermal necrolysis
}

\author{
Suja Xaviar*, Mirunalini Ravichandran
}

Department of Pharmacology, JIPMER, Puducherry, India

Received: 04 March 2020

Accepted: 07 April 2020

\section{*Correspondence:}

Dr. Suja Xaviar,

Email: sujaxaviar@gmail.com

Copyright: (C) the author(s), publisher and licensee Medip Academy. This is an open-access article distributed under the terms of the Creative Commons Attribution Non-Commercial License, which permits unrestricted non-commercial use, distribution, and reproduction in any medium, provided the original work is properly cited.

\begin{abstract}
Toxic epidermal necrolysis (TEN) is a rare life-threatening drug-induced mucocutaneous skin disease with a mortality rate of approximately $30 \%$. Nimesulide is a preferential cyclo-oxygenase (COX-2) inhibitor which is frequently used for its antipyretic, anti-inflammatory and analgesic activity. Here, we report a case of nimesulide induced toxic epidermal necrolysis in a 57 year old male patient. This patient was admitted in the hospital with symptoms of epidermal sloughing and fluid filled blisters all over the body following over the counter intake of nimesulide for fever. The drug was promptly stopped, and patient was managed with steroids, antibiotics and other adequate supportive measures. The patient showed significant recovery following stoppage of drug and adequate management. This case highlights the importance of nimesulide and other NSAIDs as possible cause of TEN.
\end{abstract}

Keywords: Nimesulide, Adverse drug reactions, Toxic epidermal necrolysis

\section{INTRODUCTION}

Toxic epidermal necrolysis (TEN) is a rare, lifethreatening drug-induced skin disease with a mortality rate of approximately $30 \%{ }^{1}$

Drugs are one of the leading causes of TEN in adults. The most implicated drugs are antibiotics, nonsteroidal anti-inflammatory drugs and anticonvulsants. New potential drugs include oxcarbazepine, sulfasalazine, COX -2 inhibitors, and strontium ranelate. Other triggers include malignancies, viral infections, systemic lupus erythematosus, ultraviolet rays exposure. ${ }^{2}$

Nimesulide is a drug with COX-2 selectivity. It is being used due to its better and faster antipyretic action. Pediatric formulations of nimesulide has been banned in India since 2011 due to hepatotoxic side effects. Over the counter (OTC) prescription of the drug makes it easily accessible to the general public. Its adverse effects commonly involve the hepato-biliary, renal, cutaneous and gastrointestinal systems. ${ }^{3}$
Adverse drug reactions (ADRs) constitute a major clinical problem leading to increased healthcare costs. There is a need for an active surveillance system to detect potential ADRs.

\section{CASE REPORT}

A 57 year old male presented to the dermatology department of Kempegowda Institute of Medical Sciences, Bangalore with complaints of fever for 2 days with rashes all over the body. He developed fluid filled blisters, initially localized on the back which gradually became generalized all over the body. The lesions were associated with burning pain and itching. Patient gave history of over the counter ingestion of tablet nimesulide for fever. The rash started within few hours of ingestion of tablet nimesulide. There was no history of any other concomitant drug intake, history of allergy to any drug or history of any chronic diseases. Patient was hospitalized and nimesulide discontinued. On examination, patient was ill looking, vitals were stable. Erythematous vesicular rash was seen all over the body (Figures 1-3). 
Ocular examination revealed conjunctival congestion of both eyes with crusting of eyelids. Oral examination revealed edematous lips, ulceration with decreased mouth opening. There were ulcerations and crusting on genital mucosa. There was mucosal erosions and epidermal detachment of more than $30 \%$ of the total area of body skin. Other systemic examinations were within normal limits.

Laboratory investigations on day 1 of admission were as follows: Hb- $11 \mathrm{gm} \%$, TC- 1400 cells/cu mm, RBS- 90 $\mathrm{gm} / \mathrm{dl}$, blood urea nitrogen- $22 \mathrm{mg} / \mathrm{dl}$, bicarbonates- 25 $\mathrm{mEq} / \mathrm{l}$, platelet- 3.0 lakhs, creatinine- $1.2 \mathrm{mg} / \mathrm{dl}$. Bilirubin levels, chest X-ray, urine routine and microscopic examination all were within normal limits. HIV, Hbs Ag/anti HCV were negative.

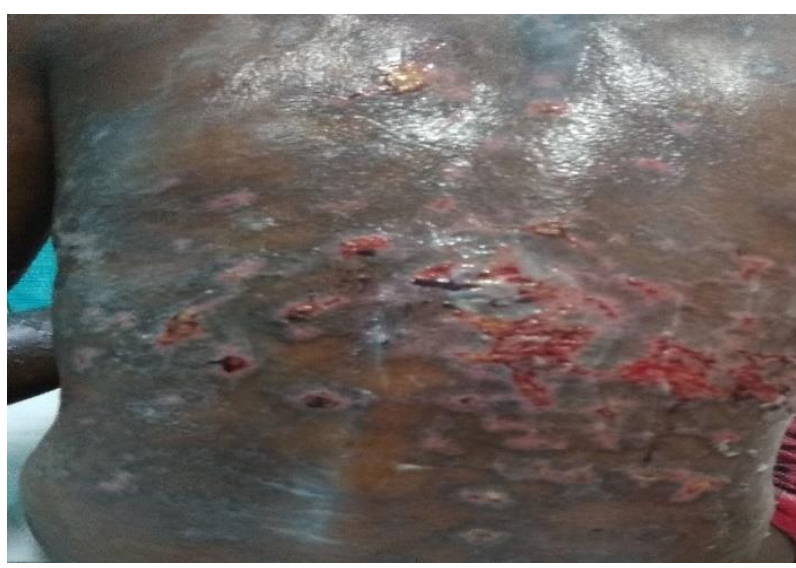

Figure 1: Multiple erosions with macules over back.

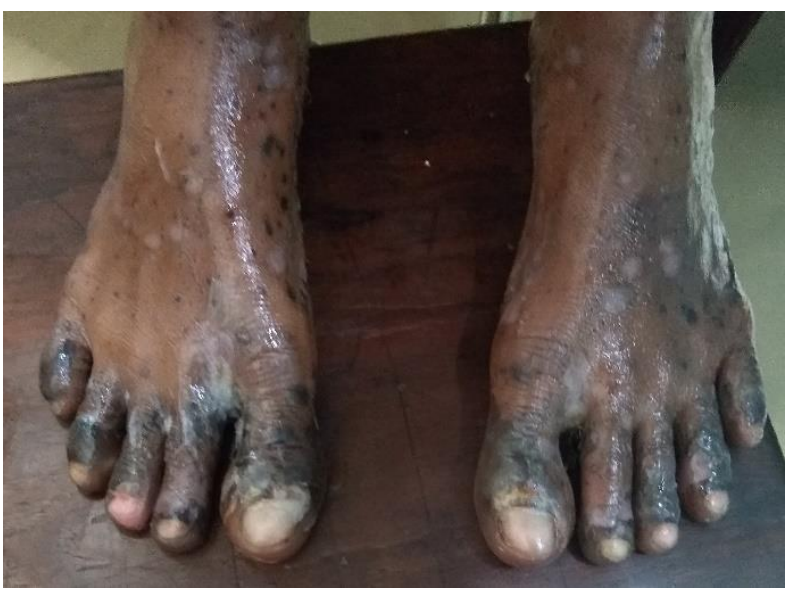

Figure 2: Erosions with hyperpigmentation over feet.

The patient was diagnosed as a case of nimesulide induced TEN on the basis of history, clinical examination and laboratory findings. The patient was managed with dexamethasone, piperacillin-tazobactam and adequate supportive measures like fluid and electrolyte management, local wound care including local anaesthetic gel for oral lesions. The patient showed significant improvement with the treatment given and was discharged, after 10 days, without any sequelae.

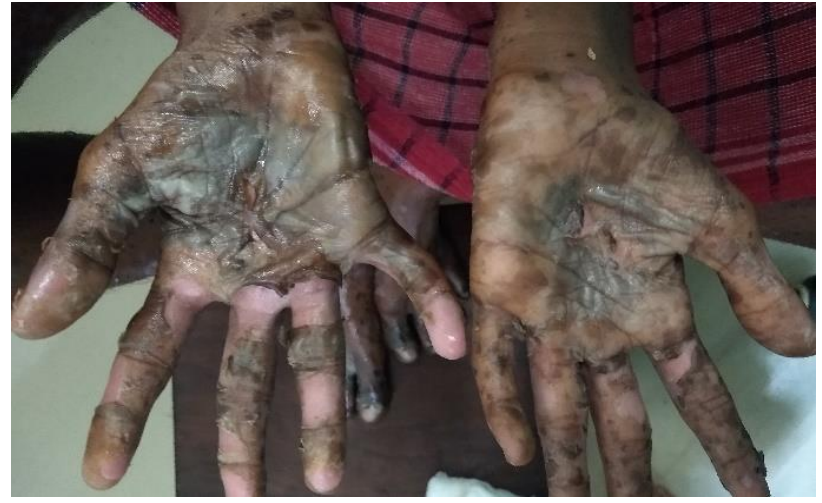

Figure 3: Erosions and exfoliations with hyperpigmented macules over hands.

\section{DISCUSSION}

ADRs can be either pharmacological reactions that are an augmentation of the known pharmacological actions of the drug or idiosyncratic reactions that are not predictable. Idiosyncratic ADRs are less common, often serious, not dose dependent, the mechanism of which is not clear, and the cause is multifactorial. This nimesulide induced TEN is a type of idiosyncratic reaction. ${ }^{4}$

TEN is a severe adverse cutaneous reaction involving skin and mucous membrane characterised by mucocutaneous tenderness, haemorrhagic erosions, erythema, epidermal detachment presenting as blisters and areas of denuded skin. ${ }^{5}$

Drugs are the main cause and some of the high-risk drugs include antibiotics, nonsteroidal anti-inflammatory drugs and anticonvulsants. The percentage of epidermal detachment is the differentiating factor between Steven Johnson syndrome (SJS) and TEN. SJS presents with $<10 \%$ epidermal detachment and TEN presents with $>30 \%$; while cases between $10 \%$ and $30 \%$ of involvement are defined as SJS-TEN overlap. This is most likely a case of drug induced TEN as other causes like upper respiratory tract infection, viral infection, or malignancy were ruled out. Since, the lesions appeared immediately after drug ingestion, systemic lupus erythematosus (SLE) was ruled out. Pemphigus was ruled out as the results of the tzanck smear were negative. TEN was diagnosed from the history and typical clinical features. Causality assessment is the method by which the extent of relationship between a drug and a suspected reaction is established. We have applied WHO-UMC scale and Naranjo's scale for the causality assessment of the event. ${ }^{6,7}$ As per the Naranjo ADR probability scale, the causality assessment score for this reaction was found to be 6 which indicates a probable causal relationship and WHO-UMC scale also showed probable causality. The event was classified to be nonpreventable under Schumock-Thornton scale. ${ }^{8}$ Hartwig's severity assessment scale was level 5. ${ }^{9}$ Scorten score was found to be 2 in this case (Table 1). Clinicians must be more vigilant while prescribing nimesulide by 
conducting regular monitoring of such patients and carrying out early diagnosis of such reactions.

There have been previous case reports of TEN caused by nimesulide showing increase in risk of TEN with nimesulide use.,10,11 Rechallenge was not done as it would not be clinically justifiable. Increased usage of nimesulide by prescription as well as OTC has led to increase in occurrence of side effects and adverse reactions.

Table 1: SCORTEN criteria for severity scoring. ${ }^{12}$

\begin{tabular}{|lll|}
\hline Prognostic factors & $\begin{array}{l}\text { Values in the } \\
\text { index case }\end{array}$ & Score \\
\hline Age & 57 years & 1 \\
\hline Heart rate & 100 & 0 \\
\hline Malignancy & No & 0 \\
\hline Body surface involved & $>50 \%$ & 1 \\
\hline Serum urea & 22 & 0 \\
\hline Serum bicarbonate & 25 & 0 \\
\hline Blood glucose & 90 & 0 \\
\hline $\begin{array}{l}\text { SCORTEN score for } \\
\text { the index case }\end{array}$ & & 2 \\
\hline
\end{tabular}

\section{CONCLUSION}

Nimesulide is a preferential cyclo-oxygenase (COX-2) inhibitor. It is being used for its antipyretic, antiinflammatory and analgesic activity. Since it is readily available as an over the counter drug (OTC) in India, these ADRs cannot be prevented. Public awareness is of vital importance to curb this menace of OTC dispensing of medicines. Medical practitioners should hence prescribe this drug with caution and closely monitor for ADRs.

Funding: No funding sources Conflict of interest: None declared

Ethical approval: Not required

\section{REFERENCES}

1. Hoetzenecker W, Mehra T, Saulite I, Glatz M, Grendelmeier SP, Guenova E, et al. Toxic epidermal necrolysis. F1000Res. 2016;5:951.
2. Wang Y, Chen C, Tassaneeyakul W, Saito Y, Aihara M, Choon SE, et al. The Medication Risk of StevensJohnson Syndrome and Toxic Epidermal Necrolysis in Asians: The Major Drug Causality and Comparison with the US FDA Label. Clin Pharma Therapeutics. 2019;105(1):112-20.

3. Chatterjee S, Pal J, Biswas N. Nimesulide-induced hepatitis and toxic epidermal necrolysis. J Postgraduate Med. 2008;54(2):150.

4. Srinivasan R, Ramya G. Adverse drug reactioncausality assessment. Int J Res Pharm Chem. 2011;1(3):606-12.

5. Rajagopalan S, Kaur S, Dogra S, Shafiq N, Bhalla A, Pandhi P, et al. Toxic Epidermal Necrolysis induced by rarely implicated drugs. Indian J Pharma. 2012;44(2):272.

6. The use of the WHO-UMC System for Standardised Case Causality Assessment. Available at: http://www.WHO-UMC.org/graphic. Accessed on 10 April 2019.

7. Naranjo CA, Busto U, Sellers EM, Sandor P, Ruiz I, Roberts EA, et al. A method for estimating the probability of adverse. Clin Pharmacol Ther. 1981;30(2):239-45.

8. Schumock GT, Thornton JP. Focusing on the preventability of adverse drug reactions. Hosp Pharm. 1992;27:538.

9. Hartwig SC, Siegel J, Schneider PJ. Preventability and severity assessment in reporting adverse drug reactions. Am J Hosp. 1992;49(9):2229-32.

10. Prameswari R, Rahman A. Nimesulide induced toxic epidermal necrolysis with hepatitis-a case report. University J Pre and Paraclin Sci. 2015;1(1):19.

11. Kumar V, Gari M, Chakraborty K, Ranjan R, Chandra A, Kumari K. Nimesulide induced toxic epidermal necrolysis: a rare case report. Int J Basic Clin Pharma. 2017;6(12):2939-42.

12. Fouchard N, Bertocchi M, Roujeau JC, Revuz J, Wolkenstein P, Garin BS. SCORTEN: A Severity of Illness Score for Toxic Epidermal Necrolysis. J Investigative Dermatology. 2000;115(2):149-53.

Cite this article as: Xaviar S, Ravichandran M. A case of nimesulide induced toxic epidermal necrolysis. Int J Basic Clin Pharmacol 2020;9:810-2. 